\title{
Feasibility Study of Group Counseling in Mental Health Education and Teaching in Colleges-A Case Study of the Intervention of Restrictive Group Sandplay Therapy on Interpersonal Adjustment of College Freshmen
}

\author{
Ji Li \\ Yancheng Teachers University, Yancheng, China \\ Email: lucky6237@126.com
}

How to cite this paper: Li, J. (2019) Feasibility Study of Group Counseling in Mental Health Education and Teaching in Colleges-A Case Study of the Intervention of Restrictive Group Sandplay Therapy on Interpersonal Adjustment of College Freshmen. Open Journal of Social Sciences, 7, 318-321.

https://doi.org/10.4236/jss.2019.712023

Received: November 28, 2019

Accepted: December 23, 2019

Published: December 26, 2019

Copyright $\odot 2019$ by author(s) and Scientific Research Publishing Inc. This work is licensed under the Creative Commons Attribution International License (CC BY 4.0).

http://creativecommons.org/licenses/by/4.0/

\begin{abstract}
Restrictive group sandplay therapy is a group sandplay therapy method with certain rules and restrictions, this treatment method is an important achievement in the localization of sandplay therapy. In this paper, the basic concept and mechanism of restrictive group chamber therapy are introduced in detail and introduce the concepts related to interpersonal adaptation of college freshmen. This paper explores the feasibility of group sandplay therapy on interpersonal adaptation of freshmen, enriches the research content of restricted group sandplay therapy, and provides references for college students' mental health education and group psychological counseling.
\end{abstract}

\section{Keywords}

Restricted Group Sandplay Therapy, College Freshmen, Interpersonal Adaptation, Feasibility

\section{The Basic Concept of Restrictive Group Sandplay Therapy}

Sandplay therapy, also known as world technique, sand table game and sand table therapy, refers to a kind of psychotherapy in which visitors choose toy models from toy shelves freely and express themselves in a special box containing fine sand, and the therapist participates in the whole process in the way of companions.

Restricted group sandplay therapy refers to group sandplay therapy under certain rules. Its treatment environment does not require many sandboxes, just a 
standard sandbox [1]. Group members are divided into rounds to make the sandplay according to the order of guessing or drawing, and all members are placed in order to complete one round. During the whole process, members cannot communicate and interact with each other in any form, which is different from the traditional group chamber therapy. Rules are to ensure the smooth progress of treatment. Restrictive factors in restrictive group sandplay therapy have already constituted an important therapeutic dimension. The compliance of group members to rules can reveal some characteristics of their personalities, which are important aspects of analyzing and understanding group therapy works.

Professor Zhang Risheng believes that the restricted group sandplay therapy is more in line with the real social life situation, it is the simulation of real social life [2]. In real life, individuals are bound to be limited, how to adjust themselves to adapt to social reality and others is a difficult process. Restrictive group sandplay therapy offers people a feeling to understand other people and learn ways to adapt to, target groups with common goals and aspirations, and each member in a group at the same time accept the range of their independence, everyone can treat each other with a sense of acceptance and group the "family", promote growth for both groups.

Restrictive group sandplay therapy can improve the body and mind based on the following basic assumptions: the individual has the drive to integrate and heal the self; the unconscious has more power than the conscious to control the individual's behavior and attitude. The shadow aspect in the individual personality needs catharsis; image as the main language of the unconscious needs to be given expression; if the spiritual component of individual mind is ignored or denied, it is easy to have psychological problems. In a free and protected environment, the negative emotions of individuals can be self-expressed, and the self-healing power can be activated, ultimately promoting the integration of the individual mind.

In addition, the existence of a "psychological field" within the group, which affects the cognition, emotion and behavior of everyone within the group, is also an important hypothesis. The restricted group sandplay is more in line with the real social living environment. In real life, not everyone can follow their own inclinations. They must live within certain rules. In the production of the group sandplay, each member has his or her own scenario, and it is inevitable that there will be conflicts and friction with other members' scenarios. At this time, the parties involved in the conflict will take the initiative to adjust themselves, mutual empathy and understanding, and finally reach a tacit understanding to achieve the integration of the group.

\section{The Concept of Interpersonal Adaptation for College Freshmen}

College stage is a special critical period in individual development. It is a period of transition and preparation from youth to adulthood, and also a period of 
preparation from learning state to work state. The adaptability of individuals to college life not only affects their study and quality of life at this stage, but also affects their work and life after entering the society. Therefore, an important indicator of college students' mental health is their adaptability in school [3].

The interpersonal adaptation of college freshmen refers to the process or state in which college freshmen can carry out normal communication with others, effectively establish harmonious interpersonal relationship and achieve interaction between themselves and others and external interpersonal environment under the circumstance that the objects and forms of communication have changed.

\section{The Possibility of Restrictive Group Sandplay Therapy to Intervene the Interpersonal Adjustment of College Freshmen}

According to previous studies and the current situation of interpersonal adaptation, it can be found that interpersonal adaptation is a common problem among freshmen. Because individual psychological counseling can only to take the form of one to one, not in a short period of time for so many students interpersonal adaptation by intervention, and group intervention can over a period of time for all members of the group at the same time, solve the common psychological problems, and through group interaction, learn positive behavior patterns, in order to promote mental health. Therefore, group intervention can be the first choice to solve the interpersonal adaptation problem of college freshmen. At the same time, college students are in the transition period from immaturity to maturity. The imbalance of psychological development in the transition period often makes them in contradiction and confusion, and they are easily troubled by bad emotions. College students at this time, however, is also the most sensitive psychological stage, longing for others to understand their own psychological and fear in the face of others doubt and alternative vision, hard to summon up courage to come to counseling room to consultants to do psychological counseling or human inner bitterness, restrictive group sandplay therapy has special advantages in the solution to this problem.

In the process of sandplay production, the consultant does not have an attitude of evaluation on the process and works of the visitors. He accepts the visitors' expressions unconditionally and fully respects individual differences to maintain the uniqueness of individual works. At the same time, sandplay therapy serves as a bridge between consciousness and unconsciousness, so that consciousness and unconsciousness can communicate on this platform, so as to alleviate the troubles caused by repressed emotions and internal conflicts. The sandplay work jointly completed by the group is the "spiritual garden" jointly created by the group members. During the process of sandplay production, the dynamic relationship between the group's interpersonal relationship and its incongruent factors will gradually be exposed, and the attitudes and feelings of each member will inevitably be projected into the small sandplay world. The 
discussion process of the sandplay can inspire the members to reflect on each other, so as to continuously coordinate and improve in the series sandplay. Therefore, the restricted group sandplay can effectively improve the interpersonal communication mode of group members, present their unconscious feedback, promote deep spiritual communication among members, and finally improve their interpersonal adaptation.

\section{Conclusion}

In school mental health education, sandplay therapy has been gradually applied and recognized, attracting students to take the initiative to participate in and experience in a unique way. College students have formed a good personality by communicating with their inner world in the process of sandplay. Especially in the adaptive stage of freshmen entering the university, more students show temporary confusion and perplexity. Sandplay therapy can make them understand their inner world and help them pass through the sensitive stage smoothly. At present, many psychological counseling centers in colleges and universities are equipped with special sandplay treatment rooms and supporting sandplay treatment tools. Psychologists who have received professional training can pay attention to freshmen's psychological adaptation in the daily work of college students' mental health, and make use of restricted group sandplay therapy to intervene freshmen's interpersonal adaptation.

\section{Conflicts of Interest}

The author declares no conflicts of interest regarding the publication of this paper.

\section{References}

[1] Chen, S.S., Xu, J., Zhang, R.S. (2006) The Effectiveness of Sandplay Therapy in Alleviating Junior High School Students' Examination Anxiety. Psychological Science, 29, 1186-1189.

[2] Li, J. (2007) On the Application of Group Sandplay Therapy in College Psychological Counseling. Journal of Hebei University Adult Education College, No. 15.

[3] Qu, Y. (2009) Effectiveness of Group Sandplay Therapy in Alleviating Individual Social Anxiety. Theoretical Discussion, No. 12. 